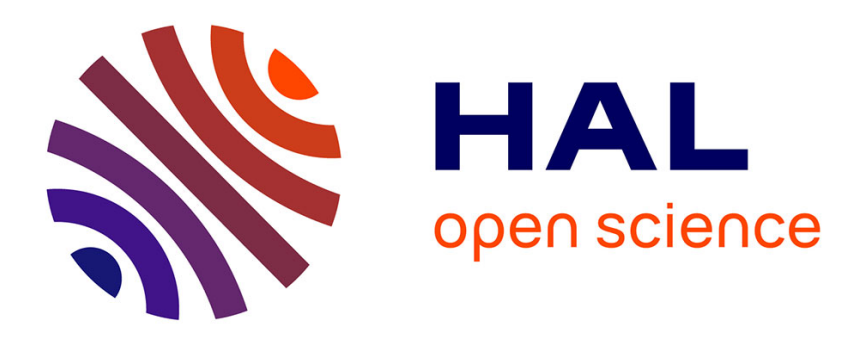

\title{
THE CRYSTALLIZATION OF Fe-Au AMORPHOUS ALLOYS
}

G. Marchal, Ph. Mangin, C. Janot

\section{To cite this version:}

G. Marchal, Ph. Mangin, C. Janot. THE CRYSTALLIZATION OF Fe-Au AMORPHOUS ALLOYS. Journal de Physique Colloques, 1975, 36 (C2), pp.C2-91-C2-95. 10.1051/jphyscol:1975219 . jpa00216267

\section{HAL Id: jpa-00216267 https://hal.science/jpa-00216267}

Submitted on 1 Jan 1975

HAL is a multi-disciplinary open access archive for the deposit and dissemination of scientific research documents, whether they are published or not. The documents may come from teaching and research institutions in France or abroad, or from public or private research centers.
L'archive ouverte pluridisciplinaire HAL, est destinée au dépôt et à la diffusion de documents scientifiques de niveau recherche, publiés ou non, émanant des établissements d'enseignement et de recherche français ou étrangers, des laboratoires publics ou privés. 


\title{
THE CRYSTALlization OF Fe-Au AMORPHOUS ALLOYS
}

\author{
G. MARCHAL, Ph. MANGIN and C. JANOT \\ Laboratoire de Physique du Solide, Université de Nancy I, C. O. 140 \\ 54037 Nancy Cedex, France
}

\begin{abstract}
Résumé. - Des alliages amorphes Fe-Au ont été obtenus en couches minces par condensation sur des substrats maintenus à la température de l'azote liquide. Les alliages de concentration $60 \%<\mathrm{Fe}<80 \%$ cristallisent en une phase métastable bcc à une température $T_{c} . T_{c}$ croît de $110 \mathrm{~K}$ à $240 \mathrm{~K}$ lorsque la concentration en fer décroît de $80 \%$ à $60 \%$ at. L'alliage $\mathrm{Fe}_{60} \mathrm{Au}_{40}$ cristallise à $550 \mathrm{~K}$ en une phase cfc. La croissance des phases bcc et cfe se fait par des processus differents.

Abstract. - Amorphous Fe-Au alloys have been obtained in the form of thin films by vapor deposition on substrates kept at liquid nitrogen temperature. Alloys containing Fe concentrations in the range $60 \%<\mathrm{Fe}<80 \%$ crystallize into a bcc metastable phase at a temperature $T_{\mathrm{e}}$ which increases from $110 \mathrm{~K}$ to $240 \mathrm{~K}$ as the Fe concentration decreases from $80 \%$ to $60 \%$. The $\mathrm{Fe}_{60} \mathrm{Au}_{40}$ alloy crystallizes at $550 \mathrm{~K}$ into a fcc phase. The growth of the bcc and fcc phases follow different process.
\end{abstract}

1. Introduction. - In the last decade a number of amorphous materials have been obtained mainly through the following three methods:

- Electroless deposition. This was used by Bagley and Turnbull [1] and Dixmier [2] for the preparation of NiP,

- Splat cooling. Introduced by Duwez [3], this technique allowed the preparation of metallic alloys containing a metalloid,

- Vapor deposition on a cold substrate. Using this vapor quenching technique, Buckel [4] and Mader [5] obtained amorphous metal alloys and Fujime [6] and Ichikawa [7] prepared pure amorphous metals.

In order to classify a film as amorphous, Mader [8] proposed three criteria :

- The diffraction pattern must show broad halos which cannot be assigned to the diffraction lines of a crystalline structure.

- High resolution micrographs must show no crystal grain structure.

- An amorphous film is capable, upon heating, to transform into a crystalline one in a very narrow temperature range. This can be observed by monitoring a property such as electrical resistivity.

We have taken these criteria as the definition of an amorphous structure. Furthermore, Mader [8] indicated the conditions necessary for the formation of an amorphous alloy by the simultaneous condensation of two metallic elements on a cold substrate :

- The phase equilibrium diagram of the alloy must show a zone where the two elements are insoluble.

- The difference between the atomic radii of the two elements must be greater than $10 \%$.

- The alloy must have close-packed components.
This last condition is not imperative.

As shown by many authors, for example Turnbull [9], the short range order (SRO) of the amorphous phase is very different from the SRO of the crystalline phase. The transformation from an amorphous to a crystalline phase require substantial reconstruction of the SRO depending upon the new crystalline phase.

We studied by electrical resistivity measurements and by electron microscopy the crystallization of amorphous Fe-Au alloys. Our choice for this alloy was dictated by our wish to have either a bcc or fcc phase after crystallization and by the conditions given by Mader [8]. Since Au has an fcc structure and Fe is bcc, one can hope for a final fcc phase for those alloys rich in $\mathrm{Au}$ and for a final bcc phase for those rich in Fe. This system satisfies the first two conditions given by Mader : the difference between the atomic radii of the two elements is $11 \%$ and for high concentrations of $\mathrm{Fe}$, $50 \%<\mathrm{Fe}<95 \%$, the occurrence of solid solutions is very limited and these appear only at high temperatures [10].

Before presenting our results we will give our experimental conditions since it is well known that the preparation of amorphous materials by evaporation is greatly influenced by a number of parameters, i. e., the pressure in the vacuum chamber during evaporation, the rate of deposition of the elements, the film thickness, the nature and the temperature of the substrate, the homogeneity of the alloy.

2. Experimental methods. - The Fe-Au alloys were prepared by vapor condensation on a substrate maintained at liquid nitrogen temperature. $\mathrm{Fe}$ of $99.99 \%$ purity was evaporated from an electron beam gun while 
Au of the same purity was evaporated from a tungsten crucible heated by the Joule effect.

The regulation of the evaporation rate is done through the use of two Kronos ADS 200 Automatic deposition control system. These were adjusted by measuring film thickness with a multiple beam interferometer Tolansky [11]. The deposition rate is of the order of $1 \AA / \mathrm{s}$. This is recorded during the evaporation and this gives an indication of the homogeneity of the alloy. Our concentration determination has an accuracy of the order of $2 \%$ and if it is supposed that at liquid nitrogen temperature, the atomic mobility on the substrate is unappreciable, one can consider that this concentration is the same in the atomic scale.

The recent studies of Bennett and Wright [12] have shown the influence of the concentration of gaseous impurities on the transition temperature of amorphous pure metals. Although in the case of alloys this influence should be smaller, we thought it better to maintain the pressure as low as possible during the evaporation.

Ultra high vacuum is attained in the evaporation chamber with the use of oil diffusion pumps. Since the pressure during the evaporation is mainly due to source outgassing, we placed a liquid nitrogen cooled Meissner trap near the evaporation sources and added a titanium sublimation pump having a high pumping rate. After 12 hours outgassing at $150^{\circ} \mathrm{C}$, the pressure in the chamber is $10^{-9}$ torr. During evaporation, the pressure is better than $2 \times 10^{-8}$ torr. This pressure is measured with a Bayard-Alpert gauge placed near the sources.

The substrates are held with silver paint to a copper block of a high thermal inertia (Fig. 1). This block is

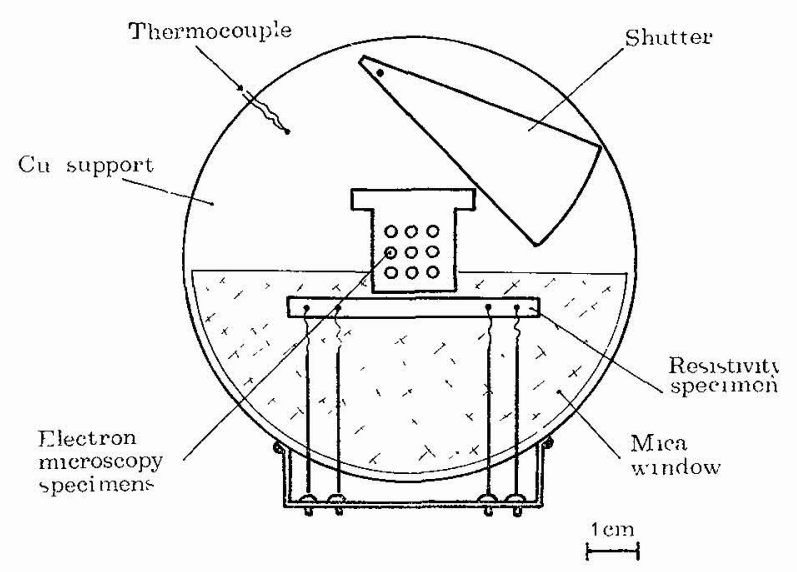

FIG. 1. - Substrate holder.

fixed at one end of a liquid nitrogen trap. The temparature of the substrates is measured with a thermocouple imbedded in the copper block. The distance sourcesubstrate is of the order of $30 \mathrm{~cm}$.

The substrates are amorphous : thin glass plates for resistivity measurements and carbon covered grids for the electron microscopy studies. A shutter covers the grids, thus stopping the deposition on these, when the alloy thickness is about $200 \AA$. The evaporation is continued until the alloy on the glass plates has reached a thickness of $1000 \AA$.

3. Experimental results. - 3.1 RESISTIVITY. - Two types of evolution have been observed in the behaviour of the electrical resistance of the alloy and the type of evolution followed depends on the alloy concentration.

$60 \%<\mathrm{Fe}<80 \%$ : The evolution of the electrical resistance is shown in the figure 2 . After condensation, the resistance $R_{\alpha}$ of the films is very much higher than that of the corresponding alloy in its crystallized state. After the initial irreversible increase of the resistance as a function of temperature, the reversible behavior described by the curve $b$ is obtained. At the temperature $T_{\mathrm{c}}$, the resistance drops abruptly and irreversibly; this temperature $T_{\mathrm{c}}$ is dependent upon the alloy concentration, being $110 \mathrm{~K}$ for $80 \% \mathrm{Fe}$ and $280 \mathrm{~K}$ for $62 \% \mathrm{Fe}$. The resistance drop spreads over an interval of $20^{\circ}$ when the heating rate of the film is $2 \% / \mathrm{min}$. After this variation, the resistance as a function of temperature is described by curve $d$ of figure 2 . The resistance drop

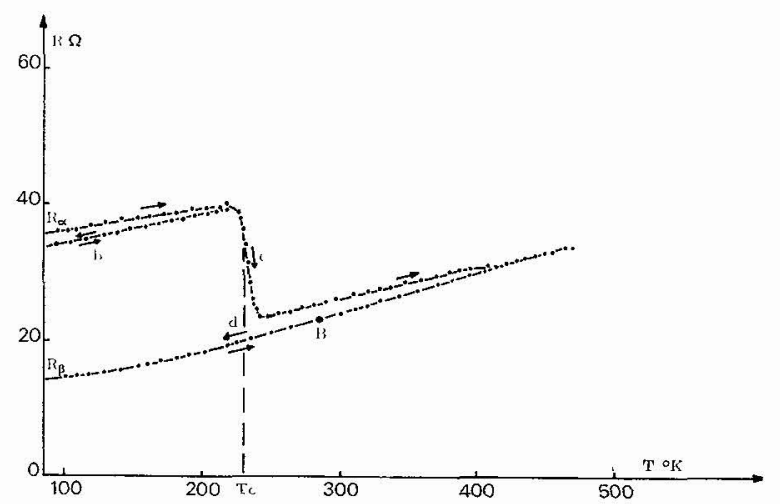

FIG. 2. - Evolution of the resistance as a function of temperature for $\mathrm{Fe}-\mathrm{Au}$ alloys containing concentrations between $60 \%$ to 80 at $\%$.

$\left(R_{\alpha}-R_{\beta}\right) / R_{\alpha}$ is approximately $60 \%$ and it decreases slightly as the concentration of $\mathrm{Fe}$ is reduced from $80 \%$ to $60 \%$.

$\mathrm{Fe} \approx 60 \%$ : The behavior of the resistance as a function of temparature as shown by figure 3 is very

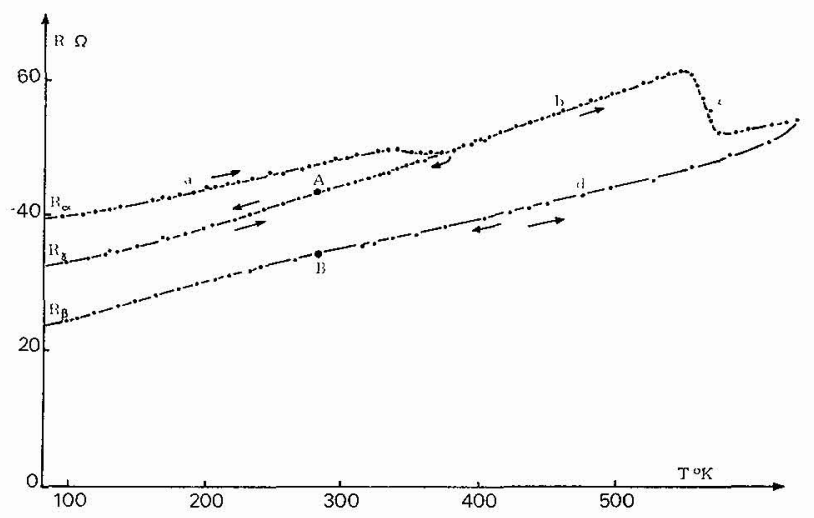

FIG. 3. - Evolution of the resistance as a function of temperature for the alloy $\mathrm{Fe}_{60} \mathrm{Au}_{40}$. 
different from that described above. After an irreversible initial portion, this behavior becomes reversible and described by curve $b$. A resistance drop appears at $550 \mathrm{~K}$ which spreads over $20^{\circ}$ for heating rate of $2 \% / \mathrm{min}$. After this drop the resistance is described by the reversible curve $d$. The resistance drop $\left(R_{\alpha}-R_{\beta}\right) / R_{\alpha}$ is of the order of $35 \%$.

3.2 ELECTRON DIFFRACTION AND MICROSCOPY. $\mathrm{Fe} \approx 60 \%:$ For this concentration the transition occurs at $550 \mathrm{~K}$ which, being much higher than the ambient temperature, makes the study of the structure of the film before and after the transition possible (point $\mathrm{A}$ and point $\mathrm{B}$ of figure 3 ).

Before the transition, the diffraction pattern (Fig. 4a) and the micrograph (Fig. 4b) show a disordered structure; The diffracticn pattern consists of broad and diffuse halos and the micrograph does not show any contrast. These two observations are features of a noncrystallized structure.

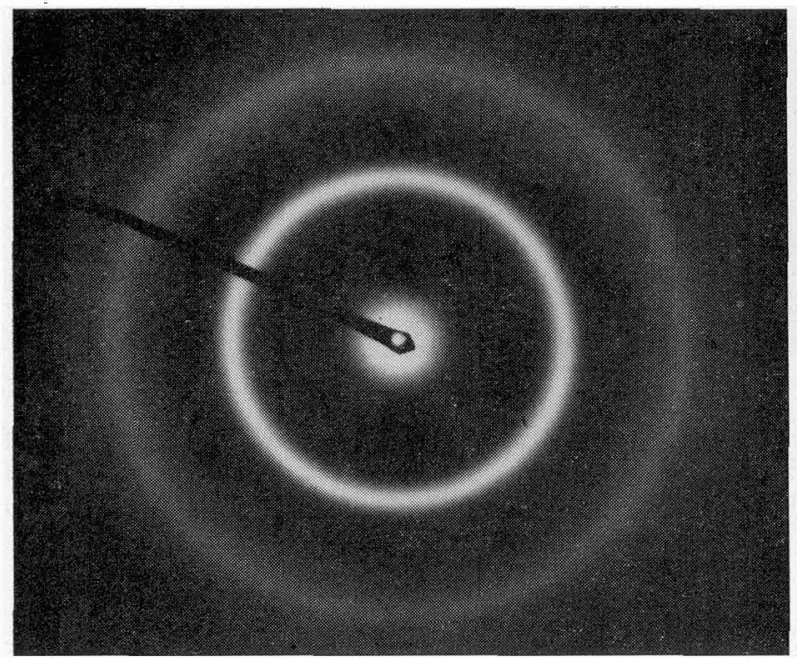

(a)

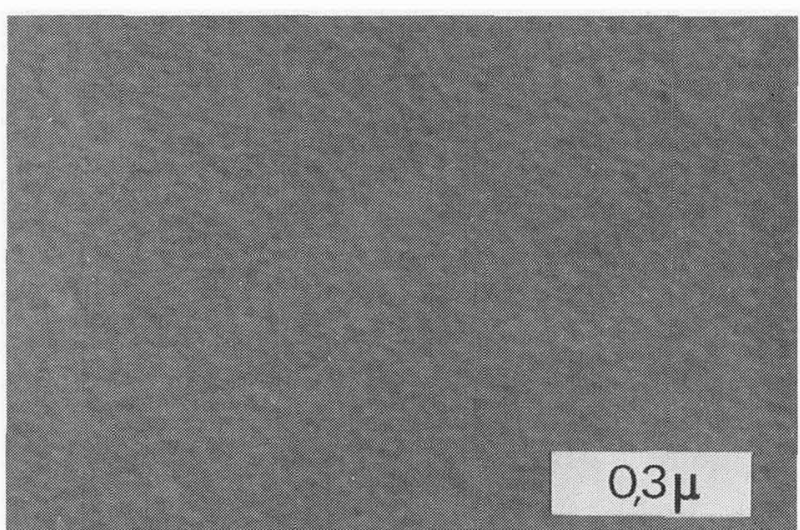

(b)

FIG. 4. - Structure of the $\mathrm{Fe}_{60} \mathrm{Au}_{40}$ alloy before the transition a) Diffraction pattern. $b$ ) Transmission electron micrograph.

After the transition the diffraction pattern (Fig. 5a) and the micrograph (Fig. $5 b$ ) reveal the existence of a crystallized phase whose structure is fcc and whose

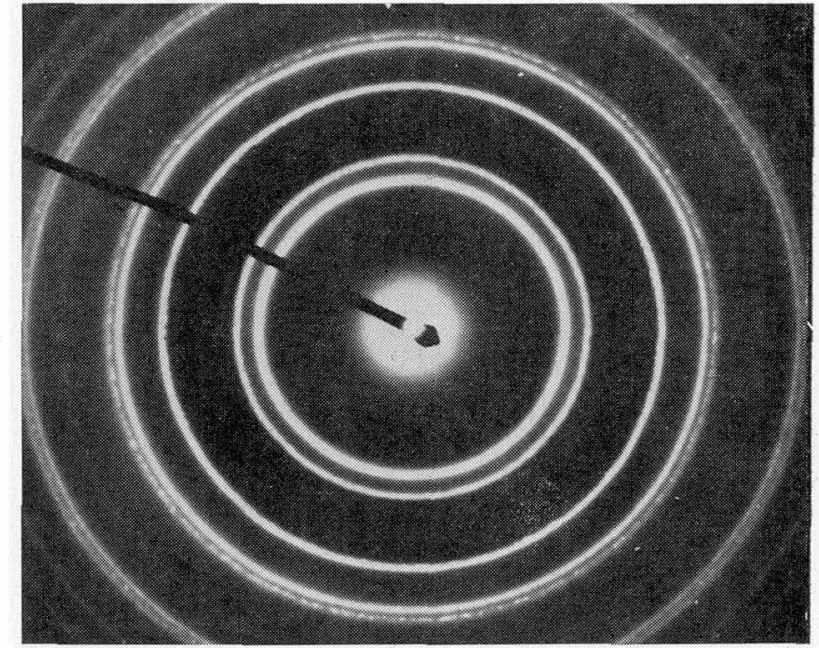

(a)

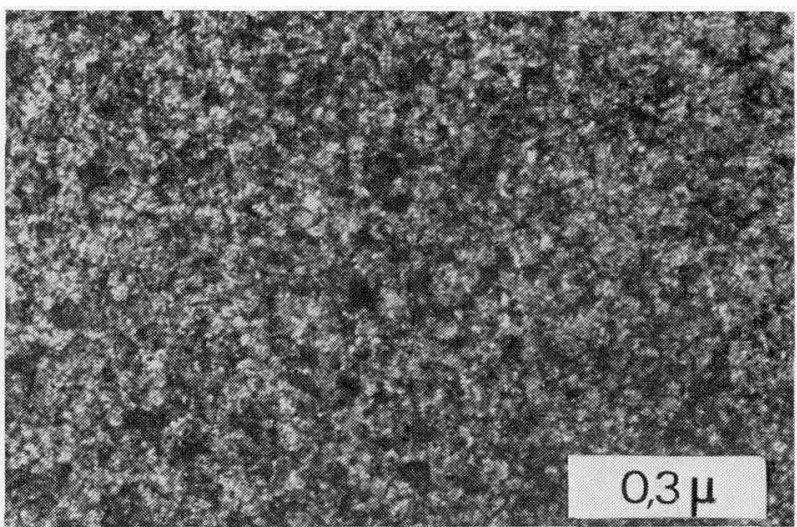

(b)

Fig. 5. - Structure of the $\mathrm{Fe}_{60} \mathrm{Au}_{40}$ alloy after the transition. a) Diffraction pattern. b) Transmission electron micrograph.

crystallite size reaches $200 \AA$. It is a metastable phase which is not found in the phase diagram; the equilibrium phase predicted by the phase diagram can only obtained after annealing the film at a temperature much higher than $600 \mathrm{~K}$.

$60 \%<\mathrm{Fe}<80 \%$ : The electron diffraction and microscopy studies were done at ambient temperature after crystallization (Fig. 2, point B).

We are of the opinion that before the resistance drop at the temperature $T_{\mathrm{c}}$, we have an amorphous structure similar to that observed for the alloy $\mathrm{Fe}_{60} \mathrm{Au}_{40}$.

After the crystallization, the diffraction pattern shows a bcc structure which, as in the case of the alloy $\mathrm{Fe}_{60} \mathrm{Au}_{40}$, is a metastable phase.

Depending upon the concentration of Fe, two types of crystallites were observed. For the concentration range of $\mathrm{Fe}$ between $70 \%$ to $80 \%$, the film is formed by an aggregate of monocrystalline crystallites whose size is about $1 \mu$. Between $60 \%$ to $70 \%$ of $\mathrm{Fe}$, the crystallites whose size attains $35 \mu$ are not monocrystalline ; the diffraction pattern shows that they lie on a (100) plane and have a texture. We further observed that there is, systematically a defect in the 


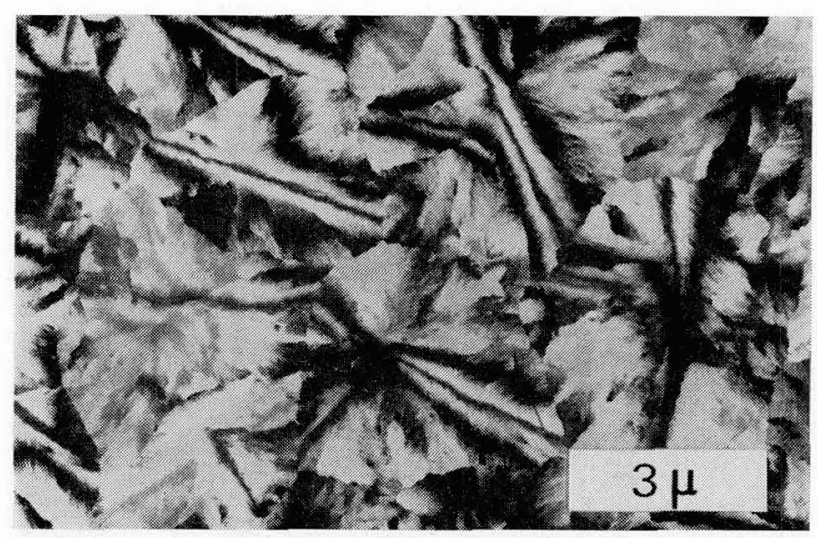

(a)

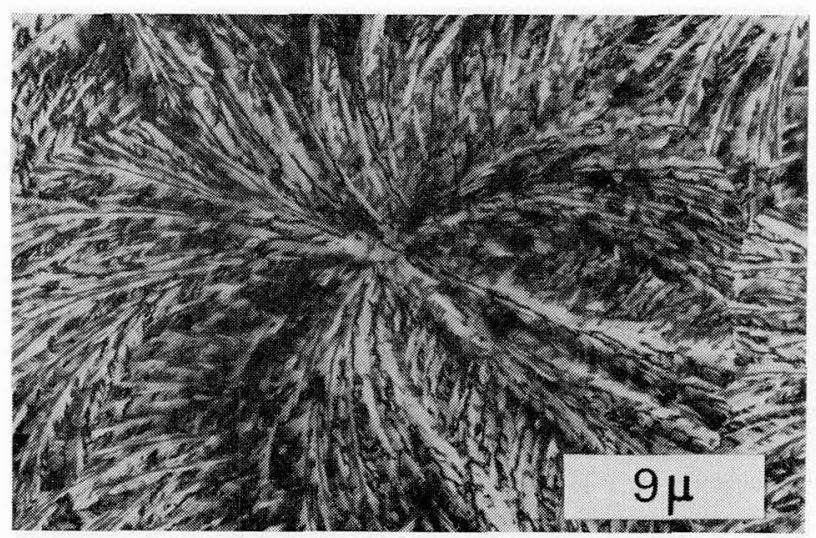

(b)

Fig. 6. - Transmission electron micrographs illustrating the crystallinity of Fe-Au alloys with $60<\mathrm{Fe}<80$ at \%. a) Monocrystalline aggregates for $70<\mathrm{Fe}<80$ at $\%$. b) Crystallites lying on the (100) plane for $60<\mathrm{Fe}<70$ at $\%$.

center of the latter crystallites (Fig. $7 b$ ) and this defect seems to be related to the nucleation of the crystallization process. We note here that this defect is inexistent in the former type of crystallites (Fig. 7a).

The transformation from an amorphous phase into a bcc phase seems to be very different from the transformation to an fcc phase as indicated by the above morphology ; in the latter, the crystallites are small and distributed at random on the substrate and in the former case, the crystallites are large and have a preferential orientation. Furthermore, the presence of Bragg fringes (Fig. $6 a$ and Fig. 7a) and fracture in the films having transformed into the bcc phase indicate the existence of considerable stresses in the crystallites.

4. Conclusion. - Our study, summarized in figure 8, can be compared to that of Felsch [13]. Felsch showed that the Fe-Au alloy deposited on a substrate maintained at liquid hydrogen temperature is amorphous when the concentration of $\mathrm{Fe}$ is within the range $45 \%$ to $97 \%$. By condensing these two elements on a substrate maintained at liquid nitrogen temperature, we have shown that an amorphous structure is obtained in the Fe concentration range between $60 \%$ to $80 \%$. Our

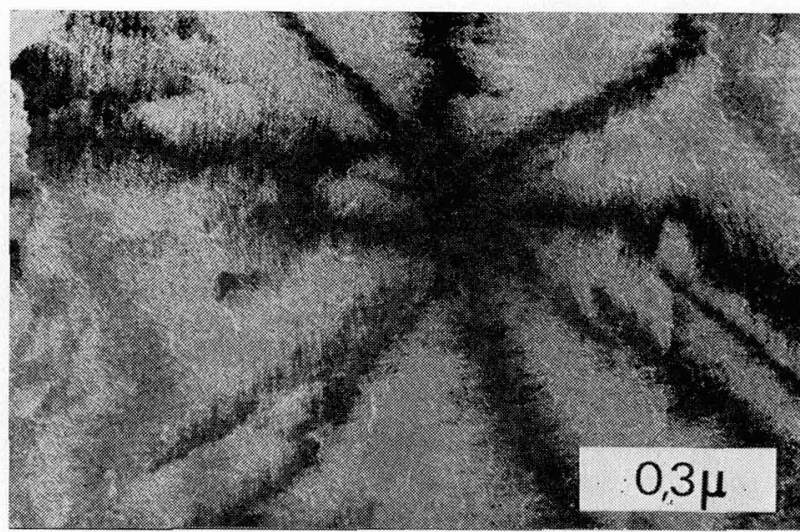

(a)

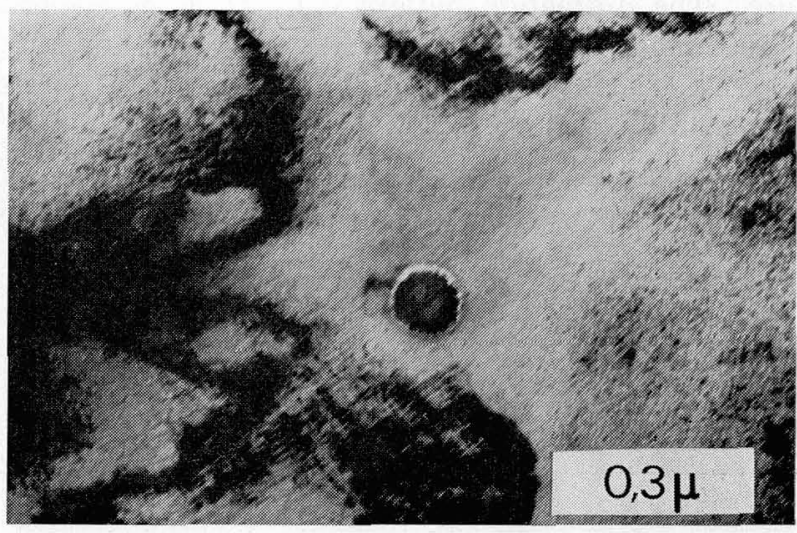

(b)

FIG. 7. - Magnification of figure 6 to show. a) The presence of Bragg fringes for $70<\mathrm{Fe}<80$ at $\%$. b) The presence of a defect at the center of a crystallite for $60<\mathrm{Fe}<70$ at $\%$.

results for alloys containing lower concentrations of $\mathrm{Fe}$ will be reported later.

By X-Ray diffraction, Felsch observed the crystallization of the amorphous phase into a bcc phase for Fe

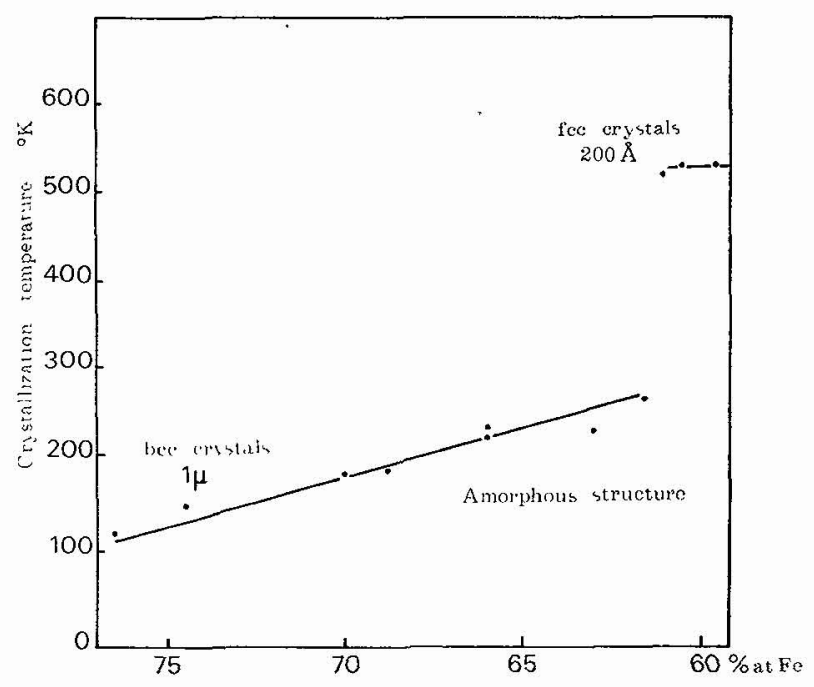

FIG. 8. - Variation of the transition temperature as a function of Fe concentration. 
concentrations greater that $65 \%$ and into an fcc phase for $\mathrm{Fe}$ concentrations lesser than $60 \%$. We partly confirm this result since we have observed that the crystallization of the alloy $\mathrm{Fe}_{60} \mathrm{Au}_{40}$ occurs at $550 \mathrm{~K}$ [14] while Felsch had always observed the growth of the crystalline phase at temperatures lower than the ambient temperature. The curve describing the evolution of the resistivity of $\mathrm{Fe}_{60} \mathrm{Au}_{40}$ (Fig. 3) shows a plateau at $20^{\circ} \mathrm{C}$ which temperature is just above that in which the alloy $\mathrm{Fe}_{62} \mathrm{Au}_{38}$ transforms into a bcc structure. This can be interpreted as a first atomic rearrangement which inhibits the formation of a bcc phase and which prepares the nucleation of the fcc phase.
We have described the morphology of the different crystallites formed. The bcc crystallites seem to be formed by nucleation at a defect and they propagate over the film surface up to sizes greater than $1 \mu$. The fcc crystallites are formed by homogeneous nucleation and their size is about $200 \AA$.

The transitions amorphous - bcc and amorphous fcc correspond to different SRO changes and we feel that the knowledge of the crystallization process is an important factor in the understanding of the amorphous phase.

We are, at present, doing some kinetics studies and $\mathrm{X}$-Ray observations which may make a quantitative evaluation of our results possible.

\section{References}

[1] Bagley, B. G., Turngull, D., Appl. Phys. 39 (1968) 5681.

[2] DixmIER, J., Thesis Orsay (1969).

[3] Duwez, P., Trans. Met. Soc. AIME 227 (1968) 362.

[4] Buckel, W., Hilsch, R., Z. Phys. 138 (1954) 109.

[5] Mader, S., J. Vac. Sci. Tech. 2 (1965) 35.

[6] Fujime, S., Japan J. Appl. Phys. 5 (1966) 764.

[7] IChIKawa, T., Phys. Stat. Sol. (b) 56 (1973) 707.

[8] MADER, S., Crystallization, grain growth and textures. American Society for metals. Metals Park, Ohio (1965).

[9] Turnbule, D., J. Physique Colloq. 35 (1974) C 4-1.
[10] Hansen, M., ANDerko, K., Constitution of binary alloys (New York, McGraw Hill) 1968.

[11] Tolanskx, S., Multiple-Beam Interferometry of Surfaces and films (Oxford University Press, Amen House, London E. C. 4) 1948.

[12] Bennett, M. R., Wright, J. D., Phys. Stat. Sol. 13A (1972) 135.

[13] FeLsCH, W., Z. Angew. Phys. 29 (1970) 217.

[14] Marchal, G., Mangin, Ph., Janot, C., To be published in Thin Solid Films 23 (1974). 